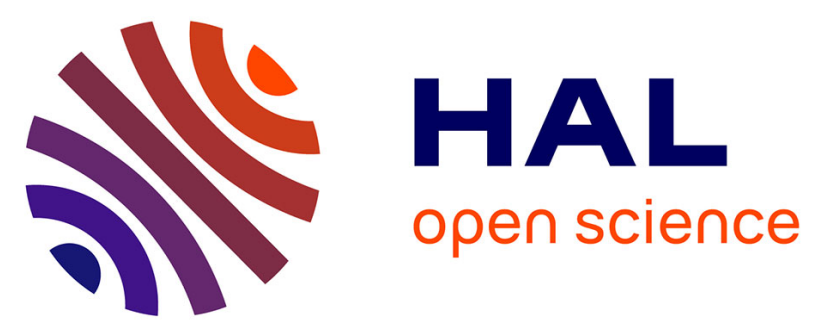

\title{
Epitaxial TiO2 Shell Grown by Atomic Layer Deposition on ZnO Nanowires Using a Double-Step Process and Its Beneficial Passivation Effect
}

Thomas Cossuet, Estelle Appert, Odette Chaix-Pluchery, Herve Roussel, Laetitia Rapenne, Gilles Renou, Frédéric Sauvage, Vincent Consonni

\section{To cite this version:}

Thomas Cossuet, Estelle Appert, Odette Chaix-Pluchery, Herve Roussel, Laetitia Rapenne, et al.. Epitaxial TiO2 Shell Grown by Atomic Layer Deposition on ZnO Nanowires Using a Double-Step Process and Its Beneficial Passivation Effect. Journal of Physical Chemistry C, 2020, 124 (24), pp.13447-13455. 10.1021/acs.jpcc.0c02605 . hal-02994844

\section{HAL Id: hal-02994844 \\ https://hal.science/hal-02994844}

Submitted on 26 Nov 2020

HAL is a multi-disciplinary open access archive for the deposit and dissemination of scientific research documents, whether they are published or not. The documents may come from teaching and research institutions in France or abroad, or from public or private research centers.
L'archive ouverte pluridisciplinaire HAL, est destinée au dépôt et à la diffusion de documents scientifiques de niveau recherche, publiés ou non, émanant des établissements d'enseignement et de recherche français ou étrangers, des laboratoires publics ou privés. 


\section{Epitaxial $\mathrm{TiO}_{2}$ Shell Grown by Atomic Layer Deposition on $\mathrm{ZnO}$}

Nanowires Using a Double-Step Process and Its Beneficial

\section{Passivation Effect}

Thomas Cossuet, ${ }^{1}$ Estelle Appert, ${ }^{1}$ Odette Chaix-Pluchery, ${ }^{1}$ Hervé Roussel, ${ }^{1}$ Laetitia Rapenne, ${ }^{1}$ Gilles Renou, ${ }^{2}$ Frédéric Sauvage, ${ }^{3}$ and Vincent Consonni. ${ }^{1 *}$

${ }^{1}$ Univ. Grenoble Alpes, CNRS, Grenoble INP, LMGP, F-38000 Grenoble, France

${ }^{2}$ Univ. Grenoble Alpes, CNRS, Grenoble INP, SIMaP, F-38042 Saint-Martin d'Hères, France

${ }^{3}$ Laboratoire de Réactivité et Chimie des Solides, Université de Picardie Jules Verne, CNRS UMR7314, 33 Rue St-Leu, 80039 Amiens cedex, France

\section{*Corresponding Author:}

Vincent Consonni

LMGP, Grenoble INP - Minatec, 3 parvis Louis Néel - CS 50257 - 38016 Grenoble cedex 1 Tel : (+33) 456529358

vincent.consonni@grenoble-inp.fr 


\section{ABSTRACT}

Owing to the chemical instability of $\mathrm{ZnO}$ nanowires and to its large surface area exhibiting a high density of traps, the use of a protective, passivating shell plays a major role on the performances of the related devices. We show that a conformal $\mathrm{TiO}_{2}$ shell can be grown on the $\mathrm{ZnO}$ nanowires by a double-step process using atomic layer deposition and post-deposition thermal treatment in air. An in situ analysis of the crystallisation process of the amorphous $\mathrm{TiO}_{\mathrm{x}}$ shell grown by atomic layer deposition is achieved in details by temperature-dependent Raman scattering and x-ray diffraction measurements, indicating that the crystallization starts around $280{ }^{\circ} \mathrm{C}$ in air and that only the anatase phase is formed. It is further revealed from transmission electron microscopy-based experiments that the $\mathrm{TiO}_{2}$ shell with the anatase phase is epitaxially grown on the $\mathrm{ZnO}$ nanowires with a range of orientation relationships. Interestingly, the epitaxial $\mathrm{TiO}_{2}$ shell has a beneficial passivating effect and results in the redistribution of the hydrogen-related defects in the center of $\mathrm{ZnO}$ nanowires following the post-deposition thermal treatment at $350{ }^{\circ} \mathrm{C}$, as shown by steady-state and time-resolved photoluminescence measurements. These findings demonstrate that the atomic layer deposition technique coupled with a post-deposition thermal treatment is a powerful tool to form $\mathrm{ZnO} / \mathrm{TiO}_{2}$ core-shell nanowire heterostructures with high structural and optical quality. They open the way for developing the present double-step process in other nanostructured material systems to master their related surface and interface properties. 


\section{INTRODUCTION}

$\mathrm{ZnO}$ nanowires (NWs) have received an overwhelming interest in the last decade for their integration into a large variety of nanoscale devices in the fields of piezoelectricity, ${ }^{1}$ optoelectronics, ${ }^{2-3}$ photovoltaics, ${ }^{4}$ detection, and sensing. ${ }^{5}$ In most of these devices, the control of the surface properties of $\mathrm{ZnO}$ NWs exhibiting a high aspect ratio at nanoscale dimensions is a critical issue, because their performances are largely governed by the different interfaces in the system. Owing to the high density of surface traps lying in the range of $10^{12}-5 \times 10^{13} \mathrm{~cm}^{-2}$ ${ }^{6-7}$ as well as to its chemical instability over a broad range of conditions in solution and gas phases, the covering of $\mathrm{ZnO} N W s$ by a $\mathrm{TiO}_{2}$ shell using atomic layer deposition (ALD) has been considered for many devices, specifically in the fields of photovoltaics and photocatalysis. The present combination is also favorable in these devices thanks to the type II band alignment between $\mathrm{ZnO}$ and $\mathrm{TiO}_{2}{ }^{8}$ The insertion of a $\mathrm{TiO}_{2}$ shell by ALD in dye-sensitized solar cells made of $\mathrm{ZnO} \mathrm{NWs}$ has been reported to drastically increase the open-circuit voltage and fill factor, enhancing the photo-conversion efficiency up to $7.0 \%$ by improving the interface with the dye. ${ }^{9-16}$ Similarly, Parize et al. showed that the extremely thin absorber solar cells made of $\mathrm{ZnO} / \mathrm{Sb}_{2} \mathrm{~S}_{3}$ core-shell NW heterostructures have an enhanced performance when a $\mathrm{TiO}_{2}$ shell deposited by ALD is inserted, leading to a photo-conversion efficiency of up to $2.3 \% .^{17}$ Cheng et al. showed that the insertion of a $\mathrm{TiO}_{2}$ shell deposited by ALD on $\mathrm{ZnO}$ NWs resulted in the increase in the short-circuit current density and photo-conversion efficiency in bulk heterojunction quantum dot solar cells incorporating $\mathrm{PbS}$ quantum dots, indicating the improvement of the charge carrier collection. ${ }^{18}$ The same enhancement has been reported in ZnO NW-based hybrid solar cells with $\mathrm{P}_{3} \mathrm{HT}^{19-21}$ and in ZnO NW-based halide perovskite solar cells to reach a photo-conversion efficiency of $14.35 \%{ }^{22-23}$ by using a $\mathrm{TiO}_{2}$ shell. Additionally, the photocatalytic activity of $\mathrm{ZnO} / \mathrm{TiO}_{2}$ core-shell $\mathrm{NW}$ heterostructures has been shown to outperform the one of bare $\mathrm{ZnO} \mathrm{NW}$ arrays. ${ }^{24-25}$ Eventually, the much higher chemical stability 
of $\mathrm{TiO}_{2}$ has been used to combine $\mathrm{ZnO}$ NWs with a large number of materials grown in acidic, corrosive conditions in order to benefit from their high aspect ratio. ${ }^{26}$ Overall, the $\mathrm{TiO}_{2}$ shell grown by ALD on ZnO NWs has been found to be polycrystalline with a varying degree of crystallinity with the purposes of passivating the surface traps together with improving their chemical stability. However, the comprehensive role of the $\mathrm{TiO}_{2}$ shell including the effects of its crystalline phase, its crystallization process, and the related interface properties with $\mathrm{ZnO}$ NWs is still under debate despite its primary importance in the performances of the devices.

In order to address that issue, an in situ analysis of the crystallization process of the $\mathrm{TiO}_{2}$ shell grown by ALD on ZnO NWs is achieved by temperature-dependent Raman scattering and $\mathrm{x}$-ray diffraction (XRD) measurements. The interface properties of the resulting $\mathrm{ZnO} / \mathrm{TiO}_{2}$ core-shell NW heterostructures are investigated in details by transmission electron microscopy (TEM)-based experiments as well as steady-state and time-resolved photoluminescence (PL) measurements. It is shown that the $\mathrm{TiO}_{2}$ shell with the anatase phase can epitaxially be formed on $\mathrm{ZnO}$ NWs by combining ALD with post-deposition thermal treatment in air, resulting in the fabrication of high quality $\mathrm{ZnO} / \mathrm{TiO}_{2}$ core-shell NW heterostructures with improved interface properties.

\section{EXPERIMENTAL SECTION}

$\mathrm{ZnO} \mathrm{NW}$ arrays were grown on $c$-axis oriented polycrystalline $\mathrm{ZnO}$ seed layers deposited on (001) silicon wafers, using a two-step chemical synthesis process. First, the polycrystalline $\mathrm{ZnO}$ seed layers were deposited by the sol-gel process using dip coating. To form the sol, 375 $\mathrm{mM}$ of zinc acetate dihydrate $\left(\mathrm{Zn}\left(\mathrm{CH}_{3} \mathrm{COO}\right)_{2} \cdot 2 \mathrm{H}_{2} \mathrm{O}\right.$, Sigma-Aldrich) and $375 \mathrm{mM}$ of monoethanolamine (MEA, Sigma-Aldrich) were mixed in pure ethanol. The solution was heated and stirred at $60{ }^{\circ} \mathrm{C}$ for 12 hours, and then at room temperature for 12 more hours. To form the xerogel film, silicon wafers were dipped in the solution and withdrew at the speed of $3.3 \mathrm{~mm} / \mathrm{s}$ in ambient atmosphere with a hygrometry smaller than $15 \%$. The xerogel film was 
annealed in air on a hot plate kept at $300{ }^{\circ} \mathrm{C}$ for 1 hour, and on another hot plate kept at $500{ }^{\circ} \mathrm{C}$ for 3 hours. Second, the $\mathrm{ZnO}$ seed layer-coated silicon wafers were immersed face down in a sealed beaker containing an equimolar mix of $30 \mathrm{mM}$ of zinc nitrate hexahydrate $\left(\mathrm{Zn}\left(\mathrm{NO}_{3}\right)_{2} .6 \mathrm{H}_{2} \mathrm{O}\right.$, Sigma-Aldrich) and HMTA $\left(\mathrm{C}_{6} \mathrm{H}_{12} \mathrm{~N}_{4}\right.$, Sigma-Aldrich) in deionized water. The sealed beaker containing the solution was placed in a regular oven heated at $90{ }^{\circ} \mathrm{C}$ for 3 hours.

The $\mathrm{TiO}_{2}$ shell was subsequently grown on $\mathrm{ZnO} \mathrm{NW}$ arrays at $200{ }^{\circ} \mathrm{C}$ by atomic layer deposition (ALD) using a F200 Fiji reactor from Cambridge Nanotech. Tetrakis dimethylamino titanium (TDMAT) heated at $75^{\circ} \mathrm{C}$ as titanium precursor and $\mathrm{H}_{2} \mathrm{O}$ as oxygen precursor were carried in the chamber by argon gas. Sequential pulses of TDMAT and $\mathrm{H}_{2} \mathrm{O}$ of 0.1 second followed by a purge of 10 seconds after each pulse were achieved to alternately inject titanium and oxygen precursors, respectively. The chamber pressure was set to $110 \mathrm{mTorr}$ and increased up to $210 \mathrm{mTorr}$ as the pulse proceeded. A complete sequence of 150 cycles was carried out to form an amorphous $\mathrm{TiO}_{\mathrm{x}}$ shell on $\mathrm{ZnO}$ NW arrays. Post-deposition thermal treatment in air was performed using an annealing temperature of 250,350 , and $500{ }^{\circ} \mathrm{C}$ for 3 hours.

The morphology of $\mathrm{ZnO} / \mathrm{TiO}_{2}$ core-shell $\mathrm{NW}$ heterostructures was studied by top-view and cross-sectional view field-emission scanning electron microscopy (FESEM) imaging using a ZEISS Ultra FEG-SEM. TEM specimens were prepared by scratching the $\mathrm{ZnO} / \mathrm{TiO}_{2}$ coreshell NW heterostructures using a diamond tip and put on Holey Carbon copper grid. TEM and HRTEM images were recorded with a JEOL JEM 2010 LaB6 microscope operating at $200 \mathrm{kV}$ with a $0.19 \mathrm{~nm}$ point-to-point resolution. EDS mapping was collected by STEM with a JEOL $2100 \mathrm{~F}$ FEG microscope operating at $200 \mathrm{kV}$ with a $0.2 \mathrm{~nm}$ resolution in the scanning mode and equipped with a JEOL SDD Centurio detector with a large solid angle of up to 0.98 steradians. The local structural properties of the $\mathrm{ZnO} / \mathrm{TiO}_{2}$ core-shell $\mathrm{NW}$ heterostructures were further investigated by using an automated crystal phase and orientation mapping (ACOM) with 
precession (ASTAR) system implemented in the JEOL 2100F FEG microscope. The crystal phase and orientation maps were obtained by precession of the primary electron beam around the microscope's optical axis at an angle of $1.16^{\circ}$ while collecting the electron diffraction patterns at a rate of 100 frames per second with a step size of $1 \mathrm{~nm}$.

In situ and ex situ Raman scattering measurements were performed using a Jobin Yvon/Horiba Labram spectrometer equipped with a liquid nitrogen cooled charge-coupled device detector. The $488 \mathrm{~nm}$ excitation line of an $\mathrm{Ar}^{+}$laser with a power around $2 \mathrm{~mW}$ at the sample surface was used. The light was focused to a spot size close to $1 \mu \mathrm{m}^{2}$ using a $50 \mathrm{x}$ long working distance objective. Raman spectra were calibrated at room temperature using a silicon reference sample with a theoretical position of $520.7 \mathrm{~cm}^{-1}$. The annealing temperature was controlled using a commercial Linkam heating stage (THMS600) placed under the Raman microscope, and varied in the range of $20-600^{\circ} \mathrm{C}$. In situ and ex situ XRD measurements were performed with a Rigaku SmartLab diffractometer and a Bruker D8 Advance diffractometer, respectively, using the $\mathrm{CuK} \alpha_{1}$ radiation according to the Bragg-Brentano configuration. The annealing temperature was controlled using an Anton Paar DHS 1100 chamber, and varied in the range of $20-600{ }^{\circ} \mathrm{C}$. In situ Raman spectra and XRD patterns were recorded with an acquisition time varying from 5 to 10 min depending on the annealing temperature.

Steady-state and time-resolved photoluminescence (PL) studies were carried out using an Edinburgh Instrument FLS980 spectrometer in front-face configuration. The steady-state PL spectra were measured with a continuous ozone-free xenon arc lamp $(450 \mathrm{~W})$ for excitation in a double grating Czerny-Turner monochromator for both excitation part and emission part to reach a total stray light rejection to less than $1: 10^{-10}$. Both excitation / emission slits were opened to a bandwidth of $3 \mathrm{~nm}$ for steady state. The emission was detected at $90^{\circ}$ from excitation by means of a high-gain Hamamatsu photomultiplier tube (PMT) detector mounted after the second emission monochromator. The time-resolved PL experiments were performed in single 
photon counting mode using a picosecond $375 \mathrm{~nm}$ laser diode as an excitation source $(2 \mathrm{MHz})$ and a microchannel plate PMT (MCP-PMT) Hamamatsu detector cooled at $-20^{\circ} \mathrm{C}$. This latter was settled after the first emission monochromator to minimize instrumental time resolution down to ca. $80 \mathrm{ps}$ time scale. The slit opening of the excitation monochromator was $10 \mathrm{~nm}$ wide to maximize the photon counting. A long pass filter of $410 \mathrm{~nm}$ was used to avoid the counting of incident photons directly reflected by the samples without being rejected by the monochromator. The laser energy was ca. $100 \mathrm{~nJ} / \mathrm{cm}^{2}$.

\section{RESULTS AND DISCUSSION}

\subsection{Morphology and structural properties of $\mathrm{ZnO} / \mathrm{TiO}_{2}$ core-shell nanowire}

heterostructures. The structural morphology of $\mathrm{ZnO} / \mathrm{TiO}_{2}$ core-shell $\mathrm{NW}$ heterostructures annealed at $350{ }^{\circ} \mathrm{C}$ for 3 hours in air is presented in Figure 1. ZnO NWs grown by CBD on a $c$-axis oriented polycrystalline $\mathrm{ZnO}$ seed layer by sol-gel process ${ }^{27}$ exhibit a mean diameter and length of $81 \pm 22 \mathrm{~nm}$ and $892 \pm 102 \mathrm{~nm}$, respectively, using an equimolar mix of zinc nitrate and HMTA. ${ }^{28}$ They retain the typical hexagonal facet on their top face following the ALD of the $\mathrm{TiO}_{2}$ shell. However, the surfaces on their $c$-plane top face and $m$-plane sidewalls have a granular morphology indicating the formation of the $\mathrm{TiO}_{2}$ shell. No change in the structural morphology of $\mathrm{ZnO} / \mathrm{TiO}_{2}$ core-shell NW heterostructures before and after annealing has been revealed by FESEM imaging. 

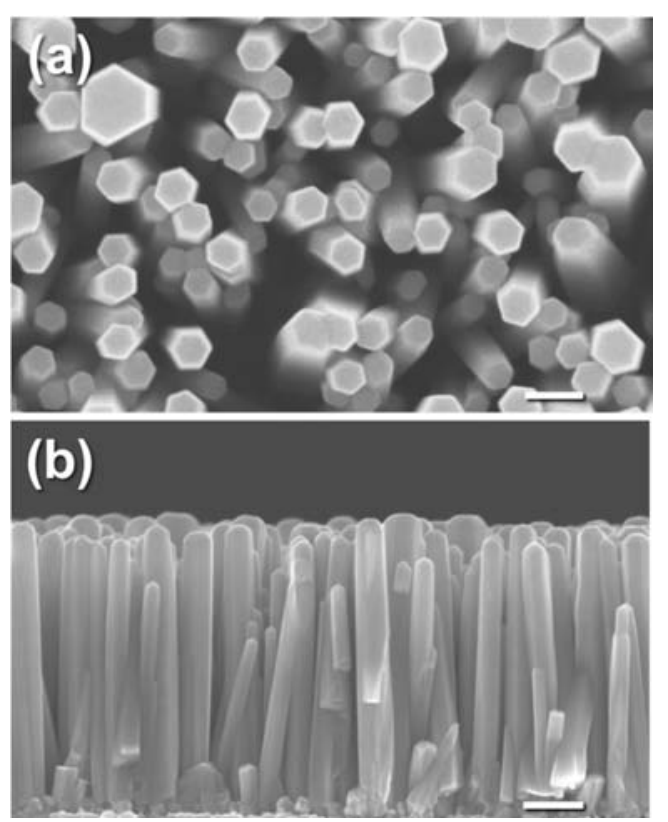

Figure 1. (a) Top-view and (b) cross-sectional view FESEM images of $\mathrm{ZnO} / \mathrm{TiO}_{2}$ core-shell $\mathrm{NW}$ heterostructures annealed at $350{ }^{\circ} \mathrm{C}$ for 3 hours in air. The scale bars denote 100 and 200 nm, respectively.

\subsection{In situ analysis of the crystallization process of $\mathrm{TiO}_{2}$ shell. In situ Raman scattering} and XRD measurements were performed from room temperature (RT) to $600{ }^{\circ} \mathrm{C}$ to thoroughly investigate the transformation of the amorphous $\mathrm{TiO}_{\mathrm{x}}$ shell into the crystallized $\mathrm{TiO}_{2}$ shell during the crystallization process. The corresponding in situ Raman spectra and XRD patterns recorded in air from RT to $600{ }^{\circ} \mathrm{C}$, and after cooling down, are presented in Figures $\mathbf{2}$ and 3, respectively. 


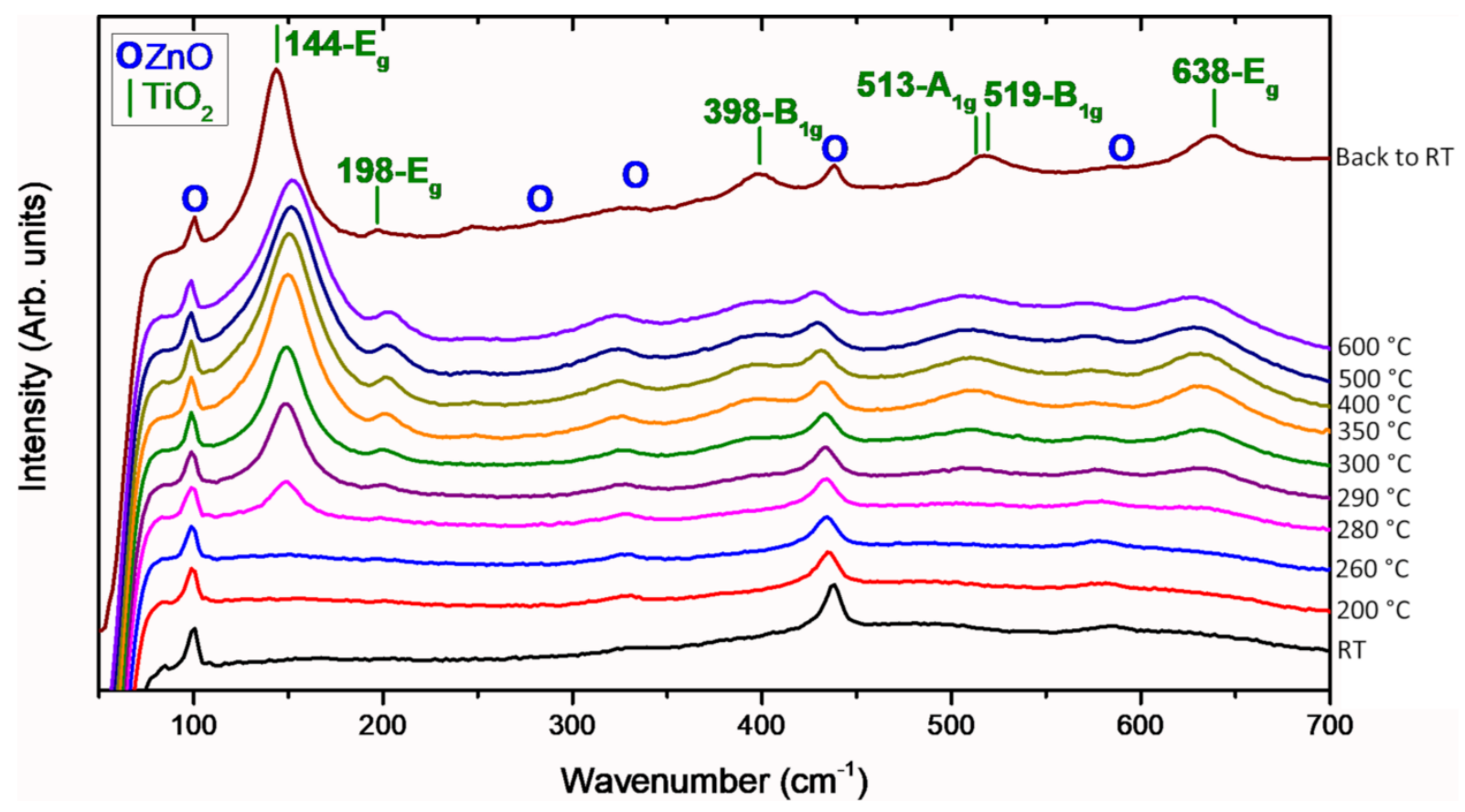

Figure 2. In situ Raman spectra of $\mathrm{ZnO} / \mathrm{TiO}_{2}$ core-shell $\mathrm{NW}$ heterostructures annealed from RT to $600{ }^{\circ} \mathrm{C}$ in air.

Prior to post-deposition thermal treatment, several well-defined lines occur in the Raman spectrum and are typically attributed to the wurtzite phase of ZnO NWs. Two intense lines at 100 and $438 \mathrm{~cm}^{-1}$ are assigned to the $\mathrm{E}_{2}^{\text {low }}$ and $\mathrm{E}_{2}{ }^{\text {high }}$ modes, respectively, while the much weaker lines at 333 and $590 \mathrm{~cm}^{-1}$ are due to the $\mathrm{E}_{2}{ }^{\text {high }}-\mathrm{E}_{2}{ }^{\text {low }}$ and $\mathrm{E}_{1}(\mathrm{LO})$ modes, respectively. ${ }^{29}$ Correlatively, the diffraction peak at $34.4^{\circ}$ is mostly ascribed to the (002) plane of the wurtzite phase of $\mathrm{ZnO}$ NWs. The diffraction peaks at $31.8,36.3,56.8$, and $62.9^{\circ}$ entirely correspond to the (100), (101), (110), and (103) planes of the wurtzite phase of polycrystalline $\mathrm{ZnO}$ seed layer. ${ }^{27}$ The Raman spectra and XRD patterns recorded from $\mathrm{RT}$ to $260^{\circ} \mathrm{C}$ are very similar to each other, showing that no drastic change occurs in the amorphous $\mathrm{TiO}_{\mathrm{x}}$ shell and thus that the crystallization process has not started in that annealing temperature range.

At the annealing temperature of $280{ }^{\circ} \mathrm{C}$, an additional line at $149 \mathrm{~cm}^{-1}$ occurs in the Raman spectrum. It is assigned to the low-frequency $\mathrm{E}_{\mathrm{g}}$ mode of the anatase phase of the $\mathrm{TiO}_{2}$ shell. ${ }^{30}$ Correlatively, a small shoulder occurs in the XRD pattern with a diffraction peak around $37.9^{\circ}$ corresponding to the (004) plane of the anatase phase of the $\mathrm{TiO}_{2}$ shell. The start of the 
crystallization process of the $\mathrm{TiO}_{\mathrm{x}}$ shell thus proceeds at $280{ }^{\circ} \mathrm{C}$ through the formation of the anatase phase. In the range of 280 to $600{ }^{\circ} \mathrm{C}$, the intensity of the Raman line at $149 \mathrm{~cm}^{-1}$ is much more pronounced and typically shifts towards higher wavenumbers while broadening, as expected from its temperature dependence. ${ }^{31}$ Also, the additional lines at 198, 398, 513, 519, and $638 \mathrm{~cm}^{-1}$ progressively occur in the Raman spectrum and are assigned to the $\mathrm{E}_{\mathrm{g}}, \mathrm{B}_{1 \mathrm{~g}}, \mathrm{~A}_{1 \mathrm{~g}}$, $\mathrm{B}_{1 \mathrm{~g}}$, and $\mathrm{E}_{\mathrm{g}}$ modes, respectively, corresponding to the anatase phase of the $\mathrm{TiO}_{2}$ shell. ${ }^{30}$ Correlatively, the intensity of the diffraction peak around $37.9^{\circ}$ slightly increases in the range of 280 to $600{ }^{\circ} \mathrm{C}$. This indicates that the crystallization process of the $\mathrm{TiO}_{2}$ shell is more active and that its crystallinity is improved in that annealing temperature range. After cooling down, all the phonon modes corresponding to the anatase phase of the $\mathrm{TiO}_{2}$ shell are clearly shown in the wavenumber range of $100-700 \mathrm{~cm}^{-1}$ while the diffraction peak around $37.9^{\circ}$ occurs, revealing that the crystallization process has efficiently been proceeded. No sign for the presence of the rutile/rocksalt phases of $\mathrm{TiO}_{2}$ is indicated, showing that the shell has crystallized into the pure anatase phase.

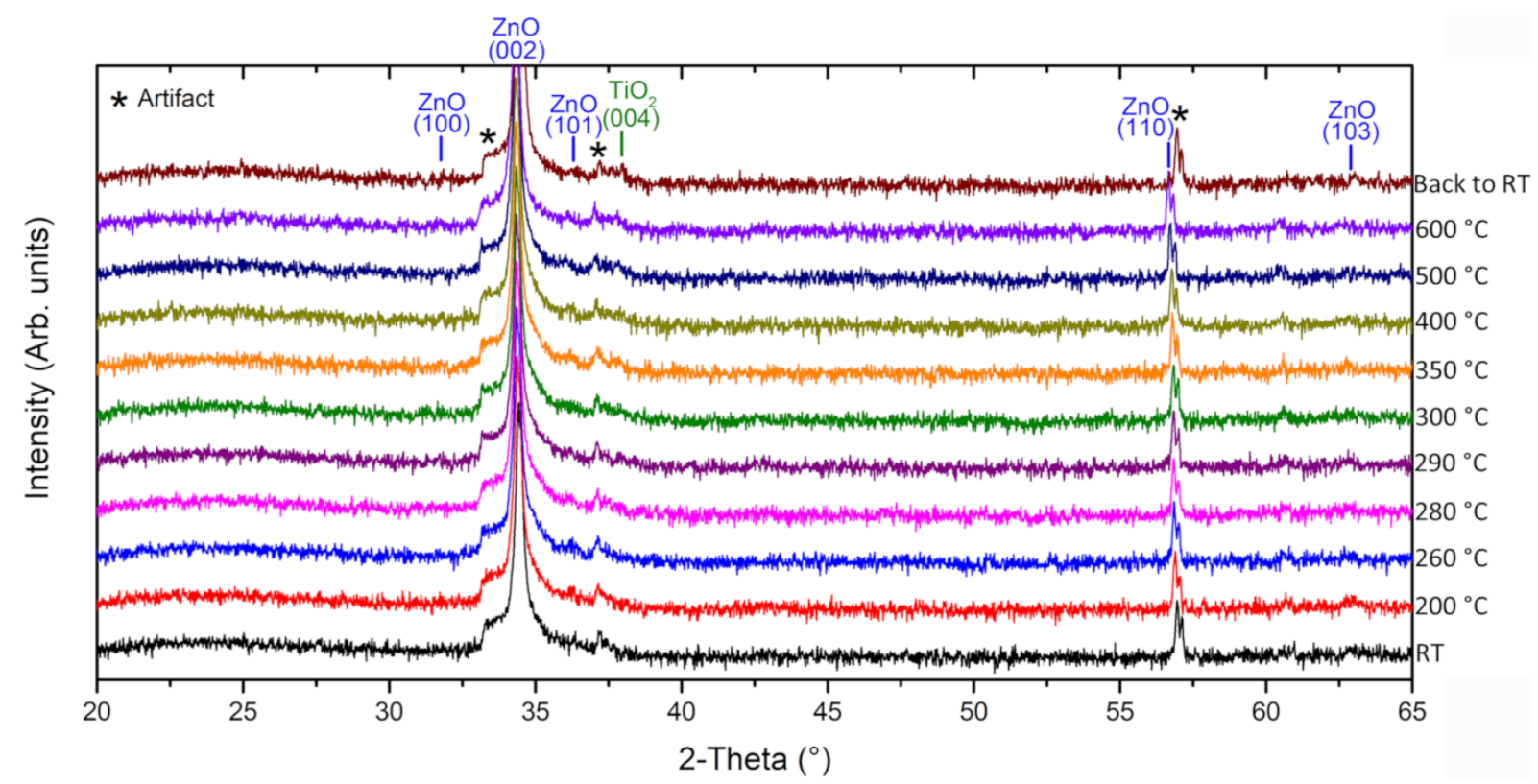

Figure 3. In situ XRD patterns of $\mathrm{ZnO} / \mathrm{TiO}_{2}$ core-shell $\mathrm{NW}$ heterostructures annealed from RT to $600{ }^{\circ} \mathrm{C}$ in air. 
An ex situ post-deposition thermal treatment of the amorphous $\mathrm{TiO}_{\mathrm{x}}$ shell on $\mathrm{ZnO} \mathrm{NWs}$ was achieved at 250,350 , and $500{ }^{\circ} \mathrm{C}$ for 3 hours in air to corroborate the in situ analysis. The corresponding XRD patterns and Raman spectra are presented in Figure S1 and S2. The XRD pattern reveals that the $\mathrm{TiO}_{\mathrm{x}}$ shell is still amorphous following the post-deposition thermal treatment at $250{ }^{\circ} \mathrm{C}$ with no sign for the presence of diffraction peaks. In contrast, the $\mathrm{E}_{\mathrm{g}}$ line at $144 \mathrm{~cm}^{-1}$ of the anatase phase already occurs in the Raman spectrum, giving direct evidence of the crystallization onset that is likely localized highly. The longer annealing time as compared to the in situ analysis is thus sufficient to very locally activate the crystallization, showing the importance of kinetic phenomena in that process. After thermal treatments at 350 and $500{ }^{\circ} \mathrm{C}$, both techniques show that the $\mathrm{TiO}_{2}$ shell is well crystallized into the anatase phase, as shown by the occurrence of the diffraction peaks at $25.3,37.9,38.6$, and $48.1^{\circ}$ that are assigned to the (101), (004), (112) and (200) planes, as well as of the Raman lines at 144, 198, 398, 513, 519,

$638 \mathrm{~cm}^{-1}$ that correspond to the $\mathrm{Eg}, \mathrm{E}_{\mathrm{g}}, \mathrm{B}_{1 \mathrm{~g}}, \mathrm{~A}_{1 \mathrm{~g}}, \mathrm{~B}_{1 \mathrm{~g}}, \mathrm{E}_{\mathrm{g}}$ modes, respectively. ${ }^{30}$ It should be noted here that the post-deposition thermal treatment in the range of $280-350{ }^{\circ} \mathrm{C}$ is compatible with the use of glass covered with a transparent conductive oxide layer as a typical substrate in the field of photovoltaics. It is not the case for the post-deposition thermal heat treatment above $500{ }^{\circ} \mathrm{C}$. Also, the integration of an amorphous $\mathrm{TiO}_{2}$ shell is not favorable for the charge carrier separation in such nanostructured solar cells. ${ }^{4}$ In the following, the interface properties between the $\mathrm{ZnO}$ NWs and $\mathrm{TiO}_{2}$ shell are thus investigated in details for the most appropriate condition using the post-deposition thermal treatment at $350^{\circ} \mathrm{C}$.

\subsection{Interface properties between the $\mathrm{ZnO}$ nanowires and $\mathrm{TiO}_{2}$ shell. $\mathrm{TEM}$ and} HRTEM images of a $\mathrm{ZnO} / \mathrm{TiO}_{2}$ core-shell NW heterostructure annealed at $350{ }^{\circ} \mathrm{C}$ for 3 hours in air are presented in Figure 4. The deposition of the $\mathrm{TiO}_{2}$ shell on the $m$-plane sidewalls of $\mathrm{ZnO} \mathrm{NW}$ is highly conformal with a constant thickness of $8.5 \mathrm{~nm}$ from its top to its bottom, as revealed in the TEM image of Figure 4a. The thickness of the $\mathrm{TiO}_{2}$ shell on the $c$-plane face 
of $\mathrm{ZnO} \mathrm{NW}$ is however slightly larger. The HRTEM image in Figure $\mathbf{4 b}$ collected close to the $\mathrm{ZnO} / \mathrm{TiO}_{2}$ interface reveals the alignment of the (0002) plane of the $\mathrm{ZnO} \mathrm{NW}$ with the (004) plane of the $\mathrm{TiO}_{2}$ shell. The related SAED pattern in Figure 4c confirms that the $\mathrm{ZnO}$ NW and $\mathrm{TiO}_{2}$ shell crystallize into the wurtzite and anatase phases, respectively. It further shows that the $\mathrm{TiO}_{2}$ shell has an orientation relationship with the $\mathrm{ZnO} \mathrm{NW}$, following the post-deposition thermal treatment at $350{ }^{\circ} \mathrm{C}$ in air.

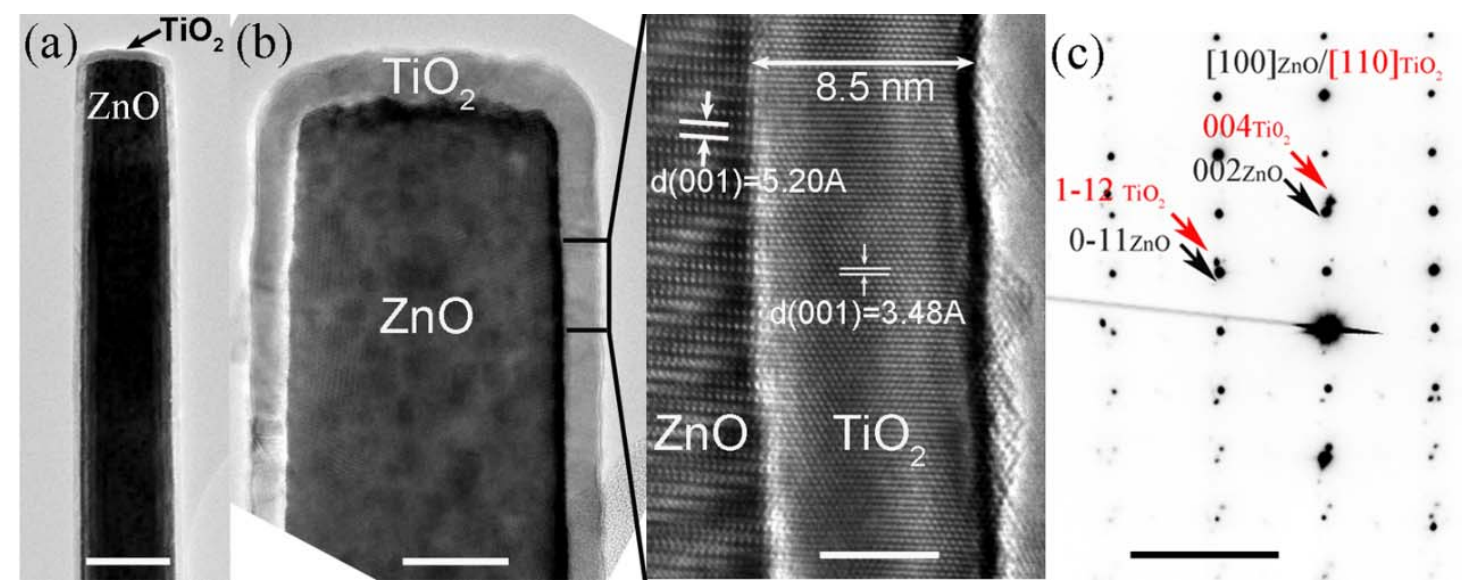

Figure 4. (a) TEM image of a $\mathrm{ZnO} / \mathrm{TiO}_{2}$ core-shell $\mathrm{NW}$ heterostructure after annealing at 350 ${ }^{\circ} \mathrm{C}$ for 3 hours in air (i.e., scale bar $=100 \mathrm{~nm}$ ). (b) Corresponding TEM image of $\mathrm{ZnO} / \mathrm{TiO}_{2}$ core-shell NW heterostructure at higher magnification (i.e., scale bar $=25 \mathrm{~nm}$ ). The inset on the right hand side shows a HRTEM image of the $\mathrm{ZnO} / \mathrm{TiO}_{2}$ interface (i.e., scale bar $=5 \mathrm{~nm}$ ). (c) Corresponding SAED pattern revealing the $\mathrm{ZnO}$ wurtzite and $\mathrm{TiO}_{2}$ anatase structures of both phases (i.e., scale bar $=5 \mathrm{~nm}^{-1}$ ).

Owing to the inherent spatial localization of the HRTEM imaging on the nanometer scale, the structural properties of the $\mathrm{TiO}_{2}$ shell and the related $\mathrm{ZnO} / \mathrm{TiO}_{2}$ interface properties were investigated on a larger scale by ASTAR measurements. ${ }^{32-33}$ In this technique, the incident electron beam had a few nanometers in size and was precessed to reduce dynamical effects and to enhance the indexing quality. The electron beam was simultaneously scanned over the area of interest to record an electron diffraction pattern at each location. The experimental electron 
diffraction patterns were basically compared with the complete set of theoretical diffraction patterns, which were computed for every expected crystalline phases and for a large number of orientations. The best match between the experimental and theoretical electron diffraction patterns permitted to identify both crystalline phase and orientation with a high precision. ${ }^{34}$ The maps of the crystalline phases and orientations of $\mathrm{ZnO} / \mathrm{TiO}_{2}$ core-shell $\mathrm{NW}$ heterostructures are presented in Figures 5 and 6, respectively.
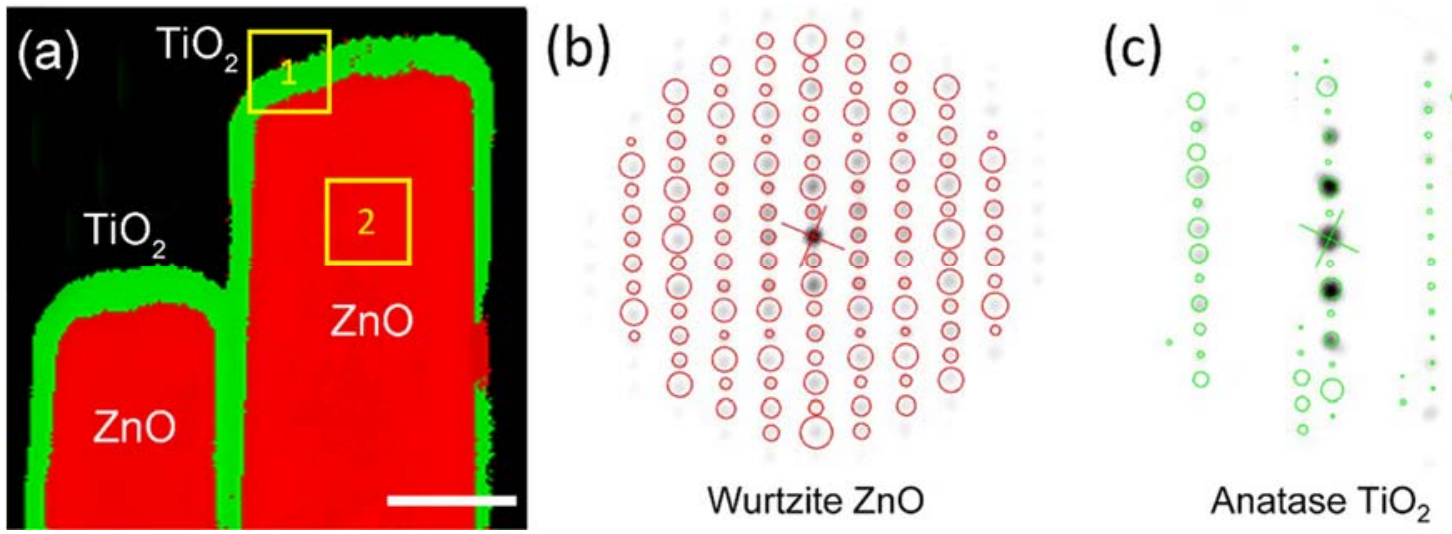

Figure 5. (a) ASTAR map representing the crystalline phases of $\mathrm{ZnO} / \mathrm{TiO}_{2}$ core-shell NW heterostructures annealed at $350^{\circ} \mathrm{C}$ for 3 hours in air (i.e., scale bar $=50 \mathrm{~nm}$ ). The $\mathrm{ZnO}$ wurtzite and $\mathrm{TiO}_{2}$ anatase phases are shown in red and green, respectively. (b, c) Corresponding electron diffraction patterns collected at points (1) and (2), respectively. The red and green open circles represent the theoretical electron diffraction patterns of wurtzite $\mathrm{ZnO}$ and anatase $\mathrm{TiO}_{2}$, respectively.

It is clearly shown in Figure 5 that the $\mathrm{TiO}_{2}$ shell on the $m$-plane sidewalls and $c$-plane face of $\mathrm{ZnO} \mathrm{NW}$ exclusively crystallizes into the anatase phase, which is in agreement with the previous Raman scattering and XRD measurements. No sign for the presence of a residual amorphous phase or of rutile/rocksalt phases or of $\mathrm{Zn}_{2} \mathrm{TiO}_{4}$ spinel phase is indicated. ${ }^{35}$ Also, the orientation map in Figure 6 reveals that the $\mathrm{TiO}_{2}$ shell is epitaxially formed on the $m$-plane sidewalls and $c$-plane face of the $\mathrm{ZnO} \mathrm{NW}$ located on the left. The orientation relationship between the $\mathrm{TiO}_{2}$ shell and $c$-plane face of $\mathrm{ZnO} \mathrm{NW}$ is the following: the (001) and (0001) 
planes as well as the (120) and (1010) planes are parallel to each other with only a very small misorientation. The orientation relationship between the $\mathrm{TiO}_{2}$ shell and $m$-plane sidewalls of the $\mathrm{ZnO} N W$ is identical and as follows: the (120) and (1010) planes as well as the (001) and (0001) planes are parallel to each other with only a very small misorientation also. It is worth noticing that the lattice mismatch between the $\mathrm{TiO}_{2}$ and $\mathrm{ZnO}$ materials lies in the range of 10 $\%$ in both orientation configurations, indicating that the epitaxial strain has completely been relieved plastically during the post-deposition thermal treatment. In contrast, the $\mathrm{TiO}_{2}$ shell formed on the $m$-plane sidewalls and $c$-plane face of nearby $\mathrm{ZnO} \mathrm{NW}$ located on the right is slightly more inhomogeneous and typically exhibits a local epitaxy with a large number of orientation relationships. Overall, the present finding shows that the epitaxial deposition of the $\mathrm{TiO}_{2}$ shell can be achieved by ALD followed by a post-deposition thermal treatment according to a double-step process, which is remarkable to get high quality $\mathrm{ZnO} / \mathrm{TiO}_{2}$ core-shell NW heterostructures. The orientation relationships are however multiple and the local epitaxy is inevitably relieved totally. It should be noted here that the epitaxial deposition by ALD has only been reported a few times in the literature regarding a couple of dedicated materials systems in a thin film configuration including $\mathrm{TiO}_{2} / \mathrm{Al}_{2} \mathrm{O}_{3} .{ }^{36}$ The structural quality of epitaxial $\mathrm{TiO}_{2}$ shell is nevertheless dependent to a small extent upon the considered $\mathrm{ZnO} \mathrm{NW}$ because the deposit of the $\mathrm{TiO}_{\mathrm{x}}$ shell by ALD is likely affected by the varying free space between the nearby $\mathrm{ZnO}$ NWs. 

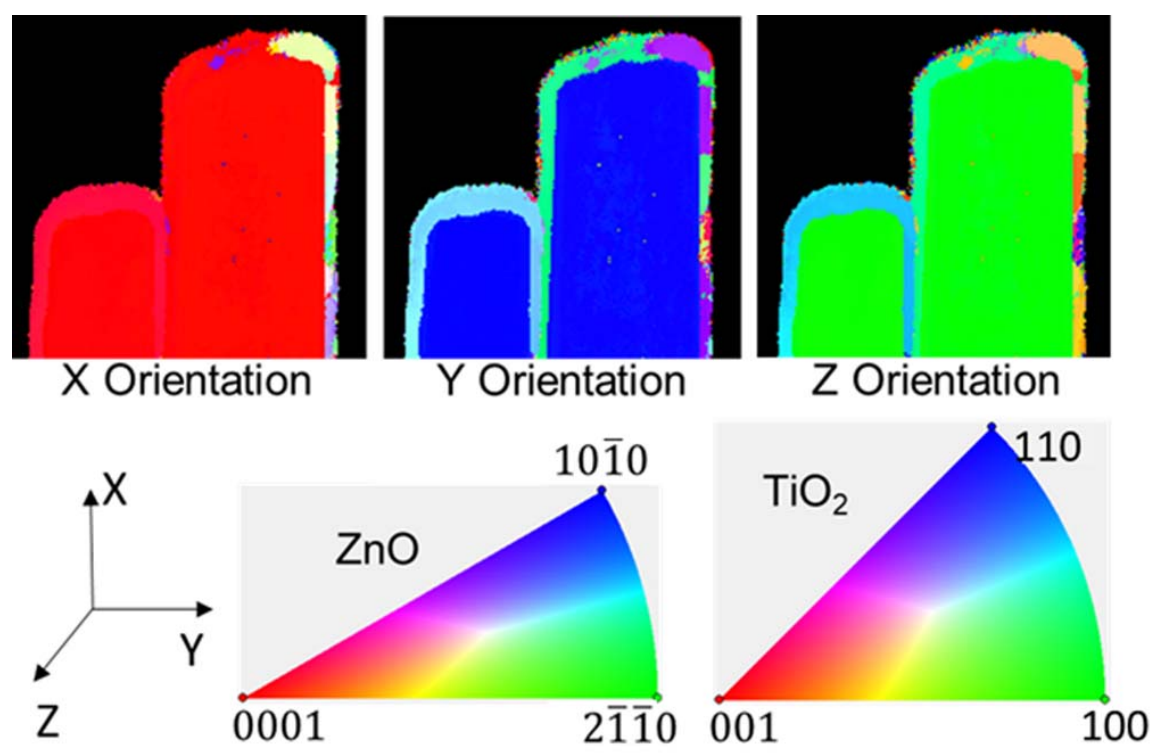

Figure 6. ASTAR maps representing the crystalline orientations of the wurtzite $\mathrm{ZnO}$ and anatase $\mathrm{TiO}_{2}$ phases within the $\mathrm{ZnO} / \mathrm{TiO}_{2}$ core-shell NW heterostructure annealed at $350{ }^{\circ} \mathrm{C}$ for 3 hours in air, plotted along the $\mathrm{X}, \mathrm{Y}$ and $\mathrm{Z}$ axes. The color scales for the wurtzite $\mathrm{ZnO}$ and anatase $\mathrm{TiO}_{2}$ phases are given in the insets.

Steady-state and time-resolved room temperature PL measurements of bare ZnO NWs and $\mathrm{ZnO} / \mathrm{TiO}_{2}$ core-shell NW heterostructures annealed at $350{ }^{\circ} \mathrm{C}$ for 3 hours in air are presented in Figures 7 and 8. The PL mapping shows that, for both samples, the spectra are composed of a sharp near-band edge (NBE) emission centered at $375 \mathrm{~nm}$ (i.e., $3.31 \mathrm{eV}$ ) and of a broad and more intense visible emission band lying in the range of $500-750 \mathrm{~nm}$ (i.e., $1.65-2.48 \mathrm{eV}$ ). The NBE emission is related to radiative bimolecular recombination processes involving neutral donor bound A-excitons, typically through the $\mathrm{I}_{4}$ and $\mathrm{I}_{5}$ lines labeled in the $\mathrm{I}$ nomenclature $\mathrm{e}^{37}$ that are assigned to substitutional hydrogen on the oxygen lattice site $\left(\mathrm{Ho}_{\mathrm{O}}\right)^{38}$ and zinc vacancy - hydrogen $\left(V_{Z n-3 H}\right)$ defect complexes, ${ }^{39}$ respectively. The involvement of interstitial hydrogen in bond-centered sites $\left(\mathrm{HBC}_{\mathrm{BC}}\right)$ is also expected in the NBE emission. ${ }^{38}$ The present hydrogen-related defects originating from the crystallization process of bare $\mathrm{ZnO} N W s$ in aqueous solution act as shallow donors and thus are responsible for their high electrical conductivity. ${ }^{40}$ In contrast, the broad visible emission band from the red/orange to yellow/green 
region stems from radiative processes involving electron-hole recombination mediated by deeper states in the bandgap of ZnO NWs. Its assignment has been a long debate over the last two decades and often attributed to oxygen vacancies for explaining the sensing properties of ZnO NWs. ${ }^{41}$ The most recent DFT calculations have however established that the emission energies related to oxygen vacancies are smaller than $1 \mathrm{eV}$ and thus cannot account for the present visible emission band obtained by optical spectroscopy. ${ }^{42}$ Instead, zinc vacancies as well as $\left(V_{Z n}-\mathrm{H}\right)$ and $\left(V_{Z n}-2 \mathrm{H}\right)$ defect complexes ${ }^{42-43}$ creating deeper states are involved both in the bulk of $\mathrm{ZnO} \mathrm{NWs}$ and on their surfaces to account for the red/orange/yellow and green/blue emission bands, respectively. Additionally, zinc dangling bonds have recently been associated with an emission energy around $2.41 \mathrm{eV} .{ }^{42}$ They may thus contribute also to the visible emission band here through their location on the surfaces of bare $\mathrm{ZnO}$ NWs. Interestingly, these two different radiative processes taking place in $\mathrm{ZnO}$ NWs are drastically modified when their surfaces are protected by the epitaxial $\mathrm{TiO}_{2}$ shell grown by ALD and crystallized by postdeposition thermal treatment in air. First, the intensity of the NBE emission is strongly enhanced. This is the result of a reduction of the monomolecular non-radiative recombination processes, which are in this case rather a surface-dominant mechanism than a bulk process owing to the high aspect ratio of ZnO NWs. Second, the broad visible emission band has almost vanished. This result is particularly insightful as it highlights that the hydrogen-related defects in the bulk of $\mathrm{ZnO}$ NWs are redistributed following the post-deposition thermal treatment in air while the one on their surfaces very likely get passivated by the epitaxial anatase- $\mathrm{TiO}_{2}$ shell. These results clarify the origin of the enhancements widely reported in the literature through $\mathrm{ZnO} / \mathrm{TiO}_{2}$ core-shell $\mathrm{NW}$ heterostructures. In particular, the epitaxial $\mathrm{TiO}_{2}$ shell affords to reduce the energy losses from the excited states of $\mathrm{ZnO}$ NWs through the passivation of surface defects, thus enhancing cell photo-voltage and charge carrier collection efficiency in photoelectrochemical devices. 

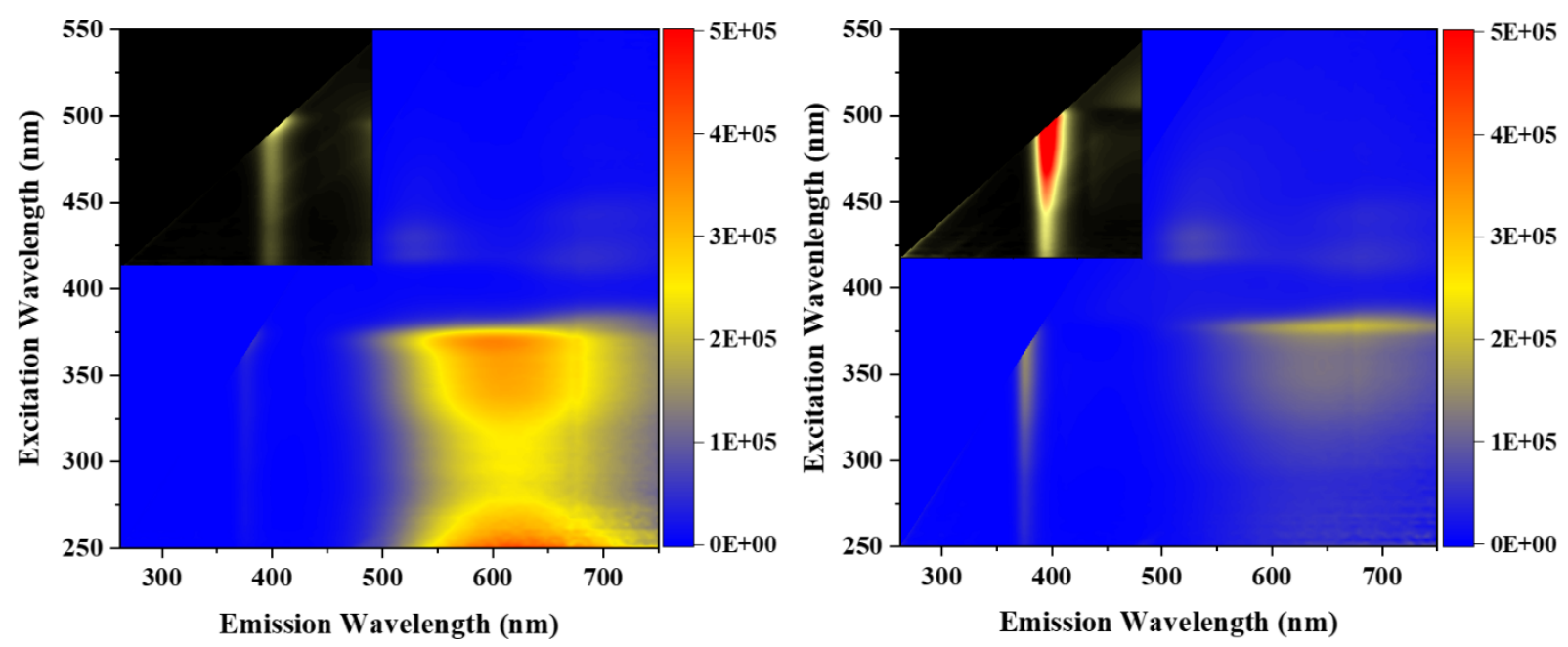

Figure 7. Steady-state room temperature PL measurements of bare $\mathrm{ZnO} \mathrm{NWs}$ (left) and $\mathrm{ZnO} /$ $\mathrm{TiO}_{2}$ core-shell NW heterostructure annealed at $350{ }^{\circ} \mathrm{C}$ for 3 hours in air (right) as a function of the excitation wavelength. The black inset corresponds to a 5 times zoom-in in intensity of the portion below $450 \mathrm{~nm}$ to better show the weaker NBE emission for sake of clarity.

The dynamic of these two radiative processes was investigated by time-correlated single photon counting (TCSPC) experiments. The two samples were excited at $375 \mathrm{~nm}$ and the PL decays were measured either in the end tail of the sharp NBE emission at $420 \mathrm{~nm}$ (Figure 8 a-b) or within the broad emission band in the visible range at $610 \mathrm{~nm}$ (Figure $8 \mathrm{c}-\mathbf{d}$ ). The evolution of the PL intensity $\mathrm{I}(\mathrm{t})$ as a function of the delay time $t$ systematically requires three simple exponential components to accurately account for the decays, as follows:

$$
I(t)=\sum_{k=1}^{n=3} f_{k} e^{-\left(\frac{t}{\tau_{k}}\right)}
$$

where $f_{\mathrm{k}}$ is the fraction of the $\mathrm{k}^{\text {th }}$ process, and $\tau_{\mathrm{k}}$ is the lifetime of the $\mathrm{k}^{\text {th }}$ process.

Although the origin of these three contributions can be debated, we favored such a mathematical function rather than a stretch bi-exponential for which the origin of lifetime distribution is also questionable. The two aforementioned radiative processes have a thoroughly different dynamic, as one could expect from their distinct origin. The decay from the NBE emission involving shallow donors is significantly faster than through the deeper traps in the visible emission band, 
as reported in Table 1. A fast component of ca. $70 \mathrm{ps}$ is deduced for the NBE emission, in addition to a second component at ca. $1 \mathrm{~ns}$ and a third component at ca. $8.3 \mathrm{~ns}$, this latter representing the predominant contribution to the decay. The presence of the epitaxial $\mathrm{TiO}_{2}$ shell slightly accelerates the PL decay and significantly promotes the fast component with a fraction increasing from $11.4 \%$ to $32.16 \%$. This suggests the possibility of a photon-induced electron transfer from the $\mathrm{ZnO} N W$ core towards the epitaxial $\mathrm{TiO}_{2}$ shell. The PL contribution from the $\mathrm{TiO}_{2}$ shell is however not detected in our case, thus suggesting a process faster than the time resolution offered by TCSPC. By probing the visible emission band at $610 \mathrm{~nm}$, the faster component of ca. $1.4 \mathrm{~ns}$ to the decay is found to be much longer. The second and third components have a lifetime of ca. $7.4 \mathrm{~ns}$ and ca. $54.2 \mathrm{~ns}$, respectively, this latter being the major contribution to the decay. In this case, the epitaxial $\mathrm{TiO}_{2}$ shell does not influence significantly the excited state dynamic of $\mathrm{ZnO}$ NWs. This can be anticipated since the deeper position of the states located in the bandgap of $\mathrm{ZnO}$ NWs cannot afford any electron transfer towards the $\mathrm{TiO}_{2}$ shell. Overall, these optical measurements indicate that the epitaxial $\mathrm{TiO}_{2}$ shell grown by ALD leads to an efficient passivating effect of the surfaces of $\mathrm{ZnO} N W s$ as well as to a redistribution of hydrogen-related defects following the post-deposition thermal treatment.

\begin{tabular}{|c|c|c|c|c|c|c|c|}
\hline & \multicolumn{7}{|c|}{ Excitation at $375 \mathrm{~nm} /$ Emission at $420 \mathrm{~nm}$} \\
\hline & $\tau_{1}(\mathrm{~ns})$ & $\mathbf{f}_{1}(\%)$ & $\tau_{2}(\mathrm{~ns})$ & $\mathbf{f}_{2}(\%)$ & $\tau_{3}(n s)$ & $\mathbf{f}_{3}(\%)$ & $\chi^{2}$ \\
\hline $\mathrm{ZnO}$ & 0.069 & 11.40 & 0.996 & 25.17 & 8.32 & 63.42 & 1.060 \\
\hline \multirow[t]{3}{*}{$\mathrm{ZnO} / \mathrm{TiO}_{2}$} & 0.067 & 32.16 & 0.724 & 27.85 & 6.70 & 39.98 & 1.149 \\
\hline & \multicolumn{7}{|c|}{ Excitation at $375 \mathrm{~nm} /$ Emission at $610 \mathrm{~nm}$} \\
\hline & $\tau_{1}(\mathbf{n s})$ & $f_{1}(\%)$ & $\tau_{2}(\mathrm{~ns})$ & $\mathbf{f}_{2}(\%)$ & $\tau_{3}(\mathbf{n s})$ & $\mathbf{f}_{3}(\%)$ & $\chi^{2}$ \\
\hline $\mathrm{ZnO}$ & 1.436 & 14.6 & 7.445 & 29.43 & 54.154 & 55.96 & 1.003 \\
\hline${\mathrm{ZnO} / \mathrm{TiO}_{2}}_{2}$ & 1.552 & 5.70 & 8.852 & 26.03 & 53.543 & 68.27 & 1.026 \\
\hline
\end{tabular}

Table 1. Lifetime $\tau_{\mathrm{k}}$ and fraction $f_{\mathrm{k}}$ values of the $\mathrm{k}^{\text {th }}$ processes obtained after reconvolution of the instrumental response function for bare $\mathrm{ZnO} \mathrm{NWs}$ and $\mathrm{ZnO} / \mathrm{TiO}_{2}$ core-shell $\mathrm{NW}$ 
heterostructures annealed at $350^{\circ} \mathrm{C}$ for 3 hours in air for an excitation wavelength at $375 \mathrm{~nm}$ and emission wavelengths at $420 \mathrm{~nm}$ or $610 \mathrm{~nm} . \chi^{2}$ is the chi value of the fit.

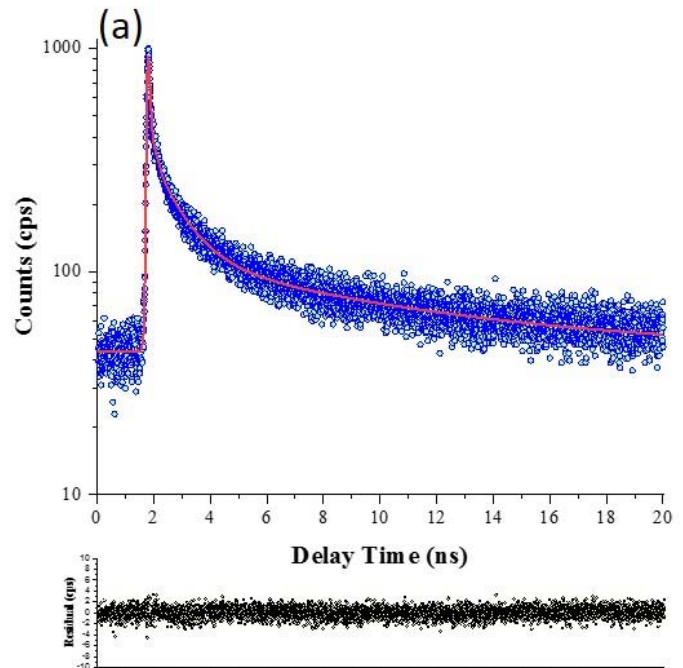

(c)

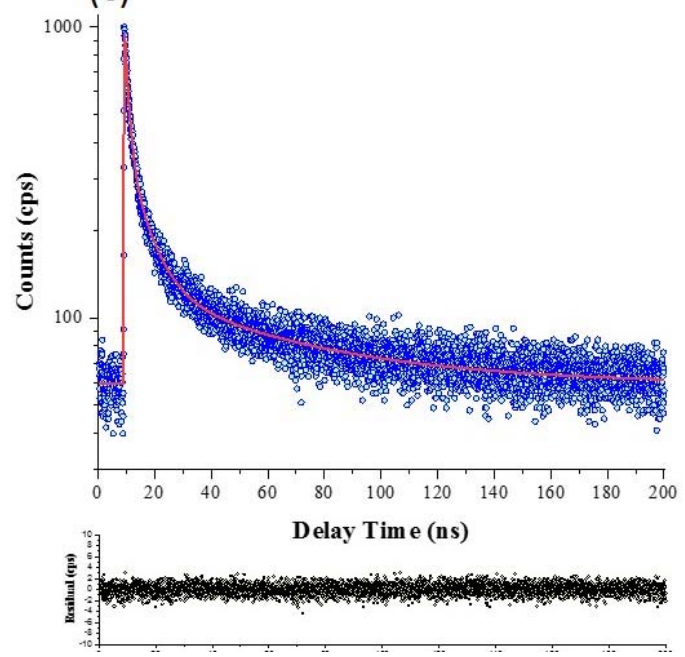

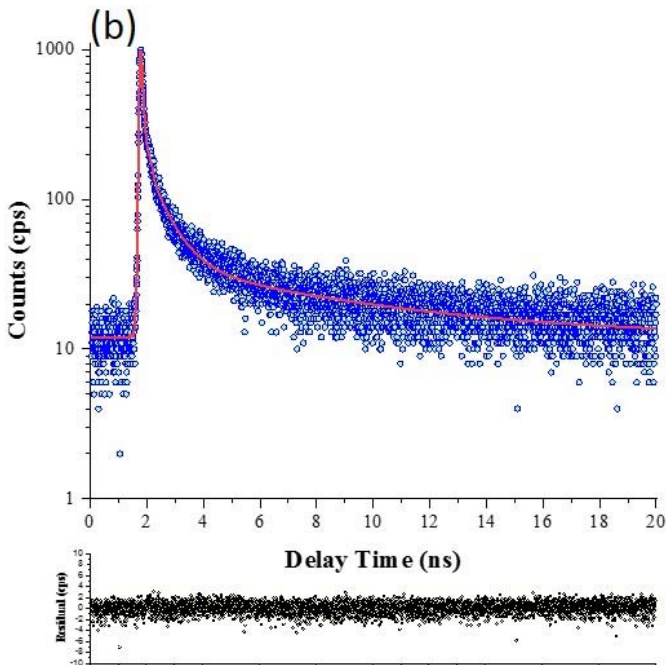

(d)

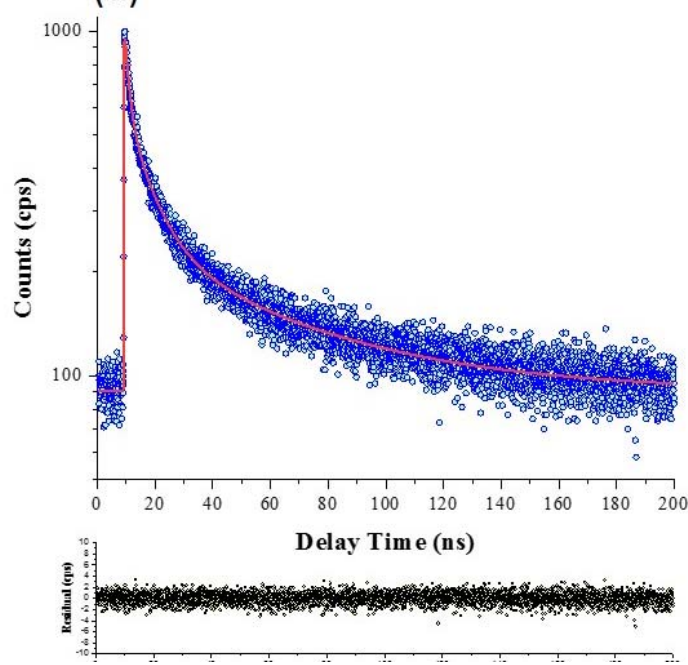

Figure 8. Time-resolved PL decay for $(\mathrm{a}, \mathrm{c})$ bare $\mathrm{ZnO} \mathrm{NWs}$ and $(\mathrm{b}, \mathrm{d}) \mathrm{ZnO} / \mathrm{TiO}_{2}$ core-shell NW heterostructures annealed at $350{ }^{\circ} \mathrm{C}$ for 3 hours in air for an excitation wavelength at 375 $\mathrm{nm}$ and emission wavelengths at (a,b) $420 \mathrm{~nm}$ or (c,d) $610 \mathrm{~nm}$ (laser repetition of $2 \mathrm{MHz}$, energy of $100 \mathrm{~nJ} / \mathrm{cm}^{2}$, long pass filter of $410 \mathrm{~nm}$ ). The blue dots correspond to the experimental data and the red curve to the experimental fits after reconvolution of the instrumental response function. The residual is reported at the bottom of each decay.

\section{CONCLUSIONS}


The chemical instability of $\mathrm{ZnO}$ NWs over a broad range of conditions in solution and gas phases as well as the high density of traps on their surfaces require the development of protective, passivating shells for improving their technological integration and maximizing the performances of the related devices. We have developed a double-step process using ALD and post-deposition thermal treatment in air to form a conformal, epitaxial $\mathrm{TiO}_{2}$ shell on the $\mathrm{ZnO}$ NWs with a range of orientation relationships, as shown by TEM-based experiments. The crystallization process has been found to start around $280{ }^{\circ} \mathrm{C}$ in air through the formation of the only anatase phase, using an in situ analysis combining temperature-dependent Raman scattering and XRD measurements. Furthermore, the epitaxial $\mathrm{TiO}_{2}$ shell has been revealed to induce a beneficial passivating effect and to redistribute the hydrogen-related defects in the center of $\mathrm{ZnO} \mathrm{NWs}$ following the post-deposition thermal treatment at $350{ }^{\circ} \mathrm{C}$ in air. The optimal conditions for the double-step process are thus compatible with the use of glass covered with a transparent conductive oxide layer as a typical substrate in the field of photovoltaics. These findings report a powerful tool to form $\mathrm{ZnO} / \mathrm{TiO}_{2}$ core-shell $\mathrm{NW}$ heterostructures with high structural and optical quality. They further open the way for developing the double-step process in other nanostructured material systems to master the related surface and interface properties.

\section{ASSOCIATED CONTENT}

XRD pattern of as-deposited $\mathrm{ZnO} / \mathrm{TiO}_{\mathrm{x}}$ core-shell $\mathrm{NW}$ heterostructures and corresponding XRD patterns obtained after annealing at 250,350 and $500^{\circ} \mathrm{C}$ for 3 hours in air (Figure S1); Raman spectrum of as-deposited $\mathrm{ZnO} / \mathrm{TiO}_{\mathrm{x}}$ core-shell NW heterostructures and corresponding Raman spectra collected after annealing at 250,350 and $500{ }^{\circ} \mathrm{C}$ for 3 hours in air (Figure S2).

\section{AUTHOR INFORMATION}

\section{Corresponding Author}

*E-mail : vincent.consonni@grenoble-inp.fr 


\section{ACKNOWLEDGEMENTS}

The authors acknowledge the financial support by the French Research National Agency through the project DOSETTE (ANR-17-CE24-0004). Funding by Cross-Disciplinary Program of the IDEX Universite Grenoble Alpes (ANR-15-IDEX-02) through the project ECO-SESA is also acknowledged. The authors further acknowledge the facilities, and the scientific and technical assistance of the CMTC characterization platform of Grenoble INP, which is supported by the Centre of Excellence of Multifunctional Architectured Materials (LabEx CEMAM) under the contract ANR-10-LABX-44-01 funded by the "Investments for the Future" Program.

\section{REFERENCES}

1. Wang, Z. L. Towards Self-Powered Nanosystems: From Nanogenerators to Nanopiezotronics. Adv. Funct. Mater. 2008, 18, 3553-3567.

2. Willander, M.; Nur, O.; Zhao, Q. X.; Yang, L. L.; Lorenz, M.; Cao, B. Q.; Zuniga-Perez, J.; Czekalla, C.; Zimmermann, G.; Grundmann, M.; et al. Zinc Oxide Nanorod Based Photonic Devices: Recent Progress in Growth, Light Emitting Diodes and Lasers. Nanotechnology 2009, 20, 40.

3. Tian, W.; Lu, H.; Li, L. Nanoscale Ultraviolet Photodetectors Based on One-Dimensional Metal Oxide Nanostructures. Nano Res. 2015, 8, 382-405.

4. Consonni, V.; Briscoe, J.; Karber, E.; Li, X.; Cossuet, T. ZnO Nanowires for Solar Cells: A Comprehensive Review. Nanotechnology 2019, 30, 41.

5. Zhu, L.; Zeng, W. Room-Temperature Gas Sensing of ZnO-Based Gas Sensor: A Review. Sens. Actuator A-Phys. 2017, 267, 242-261.

6. Zhao, Q. X.; Yang, L. L.; Willander, M.; Sernelius, B. E.; Holtz, P. O. Surface Recombination in ZnO Nanorods Grown by Chemical Bath Deposition. J. Appl. Phys. 2008, 104, 6.

7. Donatini, F.; Bugallo, A. D.; Tchoulfian, P.; Chicot, G.; Sartel, C.; Sallet, V.; Pernot, J. Comparison of Three E-Beam Techniques for Electric Field Imaging and Carrier Diffusion Length Measurement on the Same Nanowires. Nano Lett. 2016, 16, 2938-2944.

8. Wang, J.; Liu, X. L.; Yang, A. L.; Zheng, G. L.; Yang, S. Y.; Wei, H. Y.; Zhu, Q. S.; Wang, Z. G. Measurement of Wurtzite $\mathrm{ZnO} /$ Rutile $\mathrm{TiO}_{2}$ Heterojunction Band Offsets by X-Ray Photoelectron Spectroscopy. Appl. Phys. A-Mater. Sci. Process. 2011, 103, 1099-1103.

9. Law, M.; Greene, L. E.; Radenovic, A.; Kuykendall, T.; Liphardt, J.; Yang, P. D. ZnO- $\mathrm{Al}_{2} \mathrm{O}_{3}$ and ZnO-TiO ${ }_{2}$ Core-Shell Nanowire Dye-Sensitized Solar Cells. J. Phys. Chem. B 2006, 110, 22652-22663.

10. Wang, M. ; Huang, C.; Cao, Y.; Yu, Q.; Deng, Z.; Liu, Y.; Huang, Z.; Huang, J.; Huang, Q.; Guo, W.;

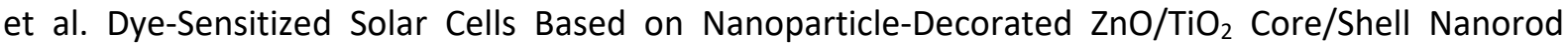
Arrays. J. Phys. D-Appl. Phys. 2009, 42, 6.

11. Xu, C. K.; Wu, J. M.; Desai, U. V.; Gao, D. Multilayer Assembly of Nanowire Arrays for DyeSensitized Solar Cells. J. Am. Chem. Soc. 2011, 133, 8122-8125. 
12. Prabakar, K.; Son, M.; Kim, W. Y.; Kim, H. TiO 2 Thin Film Encapsulated ZnO Nanorod and Nanoflower Dye Sensitized Solar Cells. Mater. Chem. Phys. 2011, 125, 12-14.

13. Irannejad, A., Janghorban, K.; Tan, O. K.; Huang, H.; Lim, C. K.; Tan, P. Y.; Fang, X.; Chua, C. S.; Maleksaeedi, S.; Hejazi, S. M. H.; et al. Effect of the $\mathrm{TiO}_{2}$ Shell Thickness on the Dye-Sensitized Solar Cells with $\mathrm{ZnO}-\mathrm{TiO}_{2}$ Core-Shell Nanorod Electrodes. Electrochim. Acta 2011, 58, 19-24.

14. Feng, Y. ; Ji, X.; Duan, J.; Zhu, J.; Jiang, J.; Ding, H.; Meng, G.; Ding, R.; Liu, J.; Hu, A.; et al. Synthesis of $\mathrm{ZnO} @ \mathrm{TiO}_{2}$ Core-Shell Long Nanowire Arrays and Their Application on Dye-Sensitized Solar Cells. J. Solid State Chem. 2012, 190, 303-308.

15. Zhao, R.; Zhu, L. P.; Cai, F. P.; Yang, Z. G.; Gu, X. Q.; Huang, J.; Cao, L. ZnO/TiO 2 Core-Shell Nanowire Arrays for Enhanced Dye-Sensitized Solar Cell Efficiency. Appl. Phys. A-Mater. Sci. Process. 2013, 113, 67-73.

16. Goh, G. K. L.; Le, H. Q.; Huang, T. J.; Hui, B. T. T. Low Temperature Grown ZnO@ $\mathrm{TiO}_{2} \mathrm{Core}$ Shell Nanorod Arrays for Dye Sensitized Solar Cell Application. J. Solid State Chem. 2014, 214, 17-23.

17. Parize, R.; Katerski, A.; Gromyko, I.; Rapenne, L.; Roussel, H.; Karber, E.; Appert, E.; Krunks, M.; Consonni, $\mathrm{V}$. $\mathrm{ZnO} / \mathrm{TiO}_{2} / \mathrm{Sb}_{2} \mathrm{~S}_{3}$ Core-Shell Nanowire Heterostructure for Extremely Thin Absorber Solar Cells. J. Phys. Chem. C 2017, 121, 9672-9680.

18. Cheng, J. J.; Chuang, C. H. M.; Hentz, O.; Rekemeyer, P. H.; Bawendi, M. G.; Gradecak, S. Dimension- and Surface-Tailored ZnO Nanowires Enhance Charge Collection in Quantum Dot Photovoltaic Devices. ACS Appl. Energy Mater. 2018, 1, 1815-1822.

19. Greene, L. E.; Law, M.; Yuhas, B. D.; Yang, P. D. ZnO-TiO 2 Core-Shell Nanorod/P3HT Solar Cells. J. Phys. Chem. C 2007, 111, 18451-18456.

20. Lee, Y. J.; Lloyd, M. T.; Olson, D. C.; Grubbs, R. K.; Lu, P.; Davis, R. J.; Voigt, J. A.; Hsu, J. W. P. Optimization of ZnO Nanorod Array Morphology for Hybrid Photovoltaic Devices. J. Phys. Chem. C 2009, 113, 15778-15782.

21. Atienzar, P.; Ishwara, T.; Illy, B. N.; Ryan, M. P.; O'Regan, B. C.; Durrant, J. R.; Nelson, J. Control of Photocurrent Generation in Polymer/ZnO Nanorod Solar Cells by Using a Solution-Processed $\mathrm{TiO}_{2}$ Overlayer. J. Phys. Chem. Lett. 2010, 1, 708-713.

22. Son, D. Y.; Bae, K. H.; Kim, H. S.; Park, N. G. Effects of Seed Layer on Growth of ZnO Nanorod and Performance of Perovskite Solar Cell. J. Phys. Chem. C 2015, 119, 10321-10328.

23. Wang, B. X.; Liu, T. F.; Zhou, Y. B.; Chen, X.; Yuan, X. B.; Yang, Y. Y.; Liu, W. P.; Wang, J. M.; Han, H. W.; Tang, Y. W. Hole-Conductor-Free Perovskite Solar Cells with Carbon Counter Electrodes Based on ZnO Nanorod Arrays. Phys. Chem. Chem. Phys. 2016, 18, 27078-27082.

24. Wang, Y.; Zheng, Y. Z.; Lu, S. Q.; Tao, X.; Che, Y. K.; Chen, J. F. Visible-Light-Responsive $\mathrm{TiO}_{2}-$ Coated ZnO:I Nanorod Array Films with Enhanced Photoelectrochemical and Photocatalytic Performance. ACS Appl. Mater. Interfaces 2015, 7, 6093-6101.

25. Mukhopadhyay, S.; Maiti, D.; Chatterjee, S.; Devi, P. S.; Kumar, G. S. Design and Application of Au Decorated $\mathrm{ZnO} / \mathrm{TiO}_{2}$ as a Stable Photocatalyst for Wide Spectral Coverage. Phys. Chem. Chem. Phys. 2016, 18, 31622-31633.

26. Parize, R.; Cossuet, T.; Appert, E.; Chaix-Pluchery, O.; Roussel, H.; Rapenne, L.; Consonni, V. Synthesis and Properties of $\mathrm{ZnO} / \mathrm{TiO}_{2} / \mathrm{Sb}_{2} \mathrm{~S}_{3}$ Core-Shell Nanowire Heterostructures Using the Silar Technique. Crystengcomm 2018, 20, 4455-4462.

27. Guillemin, S.; Appert, E.; Roussel, H.; Doisneau, B.; Parize, R.; Boudou, T.; Bremond, G.; Consonni, V. Controlling the Structural Properties of Single Step, Dip Coated ZnO Seed Layers for Growing Perfectly Aligned Nanowire Arrays. J. Phys. Chem. C 2015, 119, 21694-21703.

28. Parize, R.; Garnier, J.; Chaix-Pluchery, O.; Verrier, C.; Appert, E.; Consonni, V. Effects of Hexamethylenetetramine on the Nucleation and Radial Growth of ZnO Nanowires by Chemical Bath Deposition. J. Phys. Chem. C 2016, 120, 5242-5250.

29. Cusco, R.; Alarcon-Llado, E.; Ibanez, J.; Artus, L.; Jimenez, J.; Wang, B. G.; Callahan, M. J. Temperature Dependence of Raman Scattering in ZnO. Phys. Rev. B 2007, 75, 11.

30. Chang, H.; Huang, P. J. Thermo-Raman Studies on Anatase and Rutile. J. Raman Spectrosc. 1998, 29, 97-102. 
31. Du, Y. L.; Deng, Y.; Zhang, M. S. Variable-Temperature Raman Scattering Study on Anatase Titanium Dioxide Nanocrystals. J. Phys. Chem. Solids 2006, 67, 2405-2408.

32. Rauch, E. F.; Veron, M. Automated Crystal Orientation and Phase Mapping in Tem. Mater. Charact. 2014, 98, 1-9.

33. Midgley, P. A.; Eggeman, A. S. Precession Electron Diffraction - a Topical Review. IUCrJ 2015, 2, 126-136.

34. Consonni, V.; Rapenne, L.; Renou, G.; Roussel, H.; Gerard, L.; Cusco, R.; Artus, L.; Andre, R.; Rauch, E. F. Identifying and Mapping the Polytypes and Orientation Relationships in ZnO/CdSe CoreShell Nanowire Arrays. Nanotechnology 2016, 27, 12.

35. Yang, Y.; Scholz, R.; Fan, H. J.; Hesse, D.; Gosele, U.; Zacharias, M. Multitwinned Spinel Nanowires by Assembly of Nanobricks Via Oriented Attachment: A Case Study of $\mathrm{Zn}_{2} \mathrm{TiO}_{4}$. ACS Nano 2009, 3, 555-562.

36. Vasu, K.; Sreedhara, M. B.; Ghatak, J.; Rao, C. N. R. Atomic Layer Deposition of P-Type Epitaxial Thin Films of Undoped and N-Doped Anatase $\mathrm{TiO}_{2}$. ACS Appl. Mater. Interfaces 2016, 8, 7897-7901.

37. Meyer, B. K.; Alves, H.; Hofmann, D. M.; Kriegseis, W.; Forster, D.; Bertram, F.; Christen, J.; Hoffmann, A.; Strassburg, M.; Dworzak, M.; et al. Bound Exciton and Donor-Acceptor Pair Recombinations in ZnO. Phys. Status Solidi B-Basic Solid State Phys. 2004, 241, 231-260.

38. Lavrov, E. V.; Herklotz, F.; Weber, J. Identification of Two Hydrogen Donors in ZnO. Phys. Rev. B 2009, 79, 13.

39. Heinhold, R.; Neiman, A.; Kennedy, J. V.; Markwitz, A.; Reeves, R. J.; Allen, M. W. HydrogenRelated Excitons and Their Excited-State Transitions in ZnO. Phys. Rev. B 2017, 95, 13.

40. Cossuet, T.; Donatini, F.; Lord, A. M.; Appert, E.; Pernot, J.; Consonni, V. Polarity-Dependent High Electrical Conductivity of ZnO Nanorods and Its Relation to Hydrogen. J. Phys. Chem. C 2018, 122, 22767-22775.

41. Barbagiovanni, E. G.; Reitano, R.; Franzo, G.; Strano, V.; Terrasi, A.; Mirabella, S. Radiative Mechanism and Surface Modification of Four Visible Deep Level Defect States in ZnO Nanorods. Nanoscale 2016, 8, 995-1006.

42. Lyons, J. L.; Varley, J. B.; Steiauf, D.; Janotti, A.; Van de Walle, C. G. First-Principles Characterization of Native-Defect-Related Optical Transitions in ZnO. J. Appl. Phys. 2017, 122, 12.

43. Frodason, Y. K.; Johansen, K. M.; Bjorheim, T. S.; Svensson, B. G.; Alkauskas, A. Zn VacancyDonor Impurity Complexes in ZnO. Phys. Rev. B 2018, 97, 8. 
GRAPHICAL CONTENT

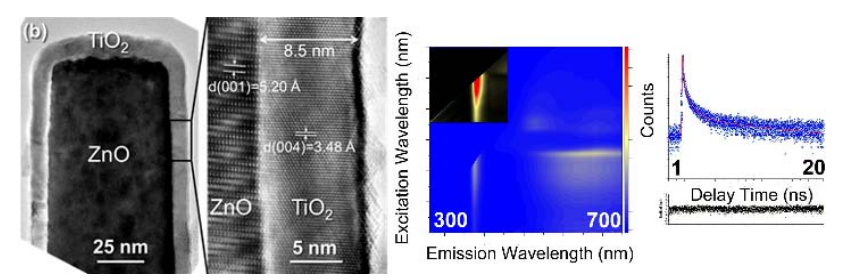

